\title{
IMPRENSA E SABER LINGÜÍSTICO: O PERCURSO DE UMA INSTITUIÇÃO
}

\section{THE PRESS AND LINGUISTIC KNOWLEDGE: THE PATHWAY OF AN INSTITUTION}

\section{Silmara Cristina Dela-Silva*}

RESUMO: Este artigo apresenta uma análise do processo de constituição da imprensa brasileira enquanto instituição que promove interpretações sobre a língua portuguesa, ao abrir espaço para colunas de especialistas sobre a língua. Para isso, soma-se às pesquisas realizadas em História das Idéias Lingüísticas, e compreende que a circulação de sentidos sobre a língua portuguesa na imprensa participa da constituição do saber sobre a língua no Brasil. O material de análise é composto pelas colunas do filólogo Cândido de Figueiredo, publicadas no Jornal do Comércio, a partir de 1900, e pelas respostas às suas publicações do também filólogo Heráclito Graça, a partir de 1903, no Correio da Manhã.

PALAVRAS-CHAVE: Língua portuguesa, imprensa brasileira, instituições, História das Idéias Lingüísticas.

ABSTRACT: This paper presents an analysis of the Brazilian press constitution process as an institution which promotes interpretation of portuguese language by giving rise to columns written by language specialists. For this purpose, it is added to the researches carried out in the History of Linguistic Ideas, and it indicates that the circulation of senses about the portuguese language in the press participates in knowledge constitution about the language in Brazil. The analysis material is composed by the columns written by the philologist Cândido de Figueiredo, published in Jornal do Comércio since 1900, and by the the answers to his publications given by Heráclito Graça, also a philologist, since 1903, in Correio da Manhã. KEY WORDS: Portuguese language, Brazilian press, institutions, The History of Linguistic Ideas.

\footnotetext{
* Doutoranda em Lingüística pela Unicamp, Campinas-SP. Mestre em Estudos Lingüísticos pela Unesp, campus de São José Rio Preto-SP, jornalista e docente de Comunicação Social, habilitações em Jornalismo e em Publicidade e Propaganda. Email: silmara.dela@uol.com.br.
} 



\section{IMPRENSA E SABER LINGÜÍSTICO: O PERCURSO \\ DE UMA INSTITUIÇÃO}

\section{Introdução}

$\mathrm{O}$ objetivo deste trabalho, que se insere entre as pesquisas realizadas na área de História das Idéias Lingüísticas, é compreender o percurso de constituição da imprensa no Brasil enquanto instituição que promove interpretações sobre o saber lingüístico ao fazer circular sentidos sobre a língua portuguesa em seus diferentes momentos no país ${ }^{1}$.

Em História das Idéias Lingüísticas ${ }^{2}$, campo de saber desenvolvido a partir de estudos com foco no processo de constituição da língua nacional e no saber metalingüístico, são consideradas instituições as entidades que se ocupam da circulação das idéias lingüísticas. A primeira instituição do Brasil, neste sentido, foi a Companhia de Jesus, que se ocupou da produção e circulação de idéias sobre a língua no Brasil, ao ter como finalidade a catequização dos índios no período da colonização brasileira.

${ }^{1}$ Este trabalho foi desenvolvido sob orientação do Prof. Dr. José Horta Nunes, do Instituto de Biociências, Letras e Ciências Exatas (Ibilce), da Universidade Estadual Paulista (Unesp), campus de São José do Rio Preto. Uma versão do trabalho em andamento foi apresentada ao GT Análise de Discurso, durante o XXI Encontro Nacional da ANPOLL - "Domínios do saber: história, instituições, práticas", realizado de 19 a 21 de julho de 2006, em São Paulo - SP.

${ }^{2}$ Sobre os primeiros estudos em História das Idéias Lingüísticas, desenvolvidos por teóricos no Brasil e na França, destacam-se as obras de Auroux (1992) e de Orlandi (2001a). 
Também são instituições os colégios, que, segundo Orlandi (2002, p. 179), "são lugares de formação", responsáveis pelo nascimento dos gramáticos no Brasil, e os congressos, locais instituídos para a discussão sobre a língua por especialistas. Segundo Orlandi (2002), a criação de instituições no Brasil, como o Colégio D. Pedro II, a Academia de Letras e a Biblioteca Nacional, "muda sobremaneira a relação do brasileiro com sua língua" (ORLANDI, 2002, p. 203), ao somar-se a normas de estabilização de uma escrita que começa a se distanciar da de Portugal ${ }^{3}$.

A imprensa institui-se igualmente como uma instituição ao fazer circular um certo conhecimento lingüístico, antes restrito a gramáticos, filólogos e estudiosos sobre a língua portuguesa, a um público amplo e não-especializado, suscitando interpretações específicas sobre a língua nacional e o saber metalingüístico. Segundo Guimarães (2004), a imprensa, a partir do final do século XIX, passa a funcionar como uma instituição social também voltada à manutenção da norma e da unidade da língua portuguesa, imaginariamente homogênea e sujeita a "deturpações".

É esta posição da imprensa, enquanto instituição social, que permite o surgimento, a partir de 1900, de colunas de especialistas nos periódicos em circulação no Brasil, para tratar de assuntos pertinentes ao uso e à constituição do português enquanto língua nacional. Para compreender o momento de aparecimento destas colunas nos periódicos brasileiros, entretanto, fazse necessário considerar as condições de produção do discurso jornalístico em território brasileiro, as características dos periódicos que passam a dedicar espaço às questões lingüísticas e dos próprios autores das colunas.

$\mathrm{O}$ presente trabalho organiza-se, desta forma, em duas partes. Na primeira, apresenta um breve resumo da imprensa em seus primeiros anos no Brasil até a sua constituição enquanto instituição que promove a circulação do saber lingüístico, ao dedicar espaço específico às questões lingüísticas por meio das colunas de especialistas; a segunda parte analisa as colunas publicadas a partir de 1900, no Jornal do Comércio ${ }^{4}$, de autoria do filólogo

\footnotetext{
${ }^{3}$ Orlandi (2002) considera que as instituições funcionam "como lugares de conhecimento legítimo, da garantia da unidade lingüística (nacional) e de domínio da 'boa' língua, da 'boa' retórica, da 'boa escrita”' (p. 179), ao tratar dos colégios enquanto instituições. Nestes termos, é possível compreender as instituições como detentoras de responsabilidades não apenas restritas à circulação do saber sobre a língua, mas também como participantes de sua produção.

${ }^{4}$ Neste trabalho, será adotada a grafia atual do nome do periódico, Jornal do Comércio.
} 
português Cândido de Figueiredo, e as respostas fornecidas às suas publicações pelo também filólogo, mas brasileiro, Heráclito Graça, a partir de 1903, em espaço análogo no jornal Correio da Manhã.

Ao materializar a imprensa enquanto instituição que se ocupa da produção e circulação do saber lingüístico, as colunas analisadas permitem compreender o papel da própria imprensa em relação à língua portuguesa no Brasil enquanto paradoxal: ao mesmo tempo em que fornece material para as considerações dos filólogos, por ser considerada responsável pelos "erros" nos usos correntes do idioma, permite a divulgação das críticas em espaço privilegiado, em suas próprias páginas, ao dar voz a especialistas em linguagem. Ao colocar novos sentidos sobre a língua portuguesa em circulação, a imprensa também constitui sentidos para a língua nacional, promovendo silenciamentos e fazendo ecoar certos dizeres sobre essa língua.

\section{A imprensa no Brasil: o nascimento de uma instituição}

Embora se constitua enquanto instituição social destinada ao controle e à manutenção da língua portuguesa apenas em 1900, ao destinar um lugar específico nas páginas de periódicos em circulação no Brasil às colunas sobre a língua portuguesa, a imprensa brasileira já se destina à circulação de idéias lingüísticas, ainda que de forma indireta, desde 1821. Nesta data, com o fim da censura prévia às publicações, uma conseqüência do retorno de D. João VI a Portugal, surgem periódicos como o Diário do Rio de Janeiro, publicados fora da Imprensa Régia e com conteúdo diverso em relação às publicações oficiais. Em suas páginas, nos diversos artigos publicados, debatem-se questões políticas e de unidade do país, que passam também pela língua nacional ${ }^{5}$.

Contudo, é apenas no final do século XIX, após 1870, conforme constata Joanilho (2005), que a questão da língua nacional efetivamente ganha espaço nos jornais, abordada em suas relações com o sujeito, a escola e o Estado. Em sua análise sobre o jornal O Estado de S. Paulo (anteriormente

\footnotetext{
${ }^{5}$ A existência de publicações que trazem à discussão a questão da língua nacional é comprovada, por exemplo, pelo Projeto Memória de Leitura, desenvolvido no Instituto de Estudos de Linguagem (IEL), da Unicamp. Na cronologia realizada com o objetivo de estudar a história do livro e da leitura no Brasil, o projeto aponta para a existência de artigos, como o publicado em 29.01.1942, no Jornal do Comércio, de autoria de José da Gama e Castro, que coloca em questão a língua nacional ao contestar a autonomia da literatura produzida no Brasil (PROJETO..., 2006).
} 
A Província de São Paulo), Joanilho divide em dois momentos a produção e circulação de artigos sobre a língua e as suas relações. No primeiro momento, em 1875 e 1876, os artigos que abordam questões lingüísticas têm como tema a naturalização de estrangeiros, a relação entre a teoria darwinista e os estudos da linguagem e a instrução pública no Brasil. Já no segundo período, que vai de 1907 a 1910, os artigos tratam do acordo ortográfico entre Brasil e Portugal e da relação entre o sujeito nacional, a escola e a língua.

O levantamento realizado por Joanilho (2005) para a constituição de seu corpus de pesquisa aponta para circulação de idéias lingüísticas nos periódicos, mesmo após 1900, não apenas nas colunas sobre o saber lingüístico especializado, mas também em outros lugares do jornal, de acordo com os assuntos em pauta no momento histórico de sua circulação. Em suas palavras, é desta forma que o "jornal põe uma relação entre instituição e textualidade, no que diz respeito às práticas relativas à língua, de forma que o que se pode dizer é que o jornal constitui (e se constitui em) espaço de reflexão/compreensão/interpretação dos sentidos sobre a língua" (JOANILHO, 2005, p. 87).

Esse aparecimento mais recorrente do saber lingüístico nos jornais, no período que compreende o final do século XIX e o começo do século XX, dá-se, de acordo com os estudos sobre a imprensa, no momento considerado a segunda fase da imprensa no Brasil, a chamada etapa de consolidação, que se inicia em 1880.

Segundo Bahia (1990), estudioso da área de comunicação jornalística, é nessa época, 72 anos após a instalação da Gazeta do Rio de Janeiro ${ }^{6}$, primeiro jornal oficial do país, que crescem os investimentos na imprensa, com a renovação dos parques gráficos. $\mathrm{O}$ crescimento se manifesta em números de jornais, que chega a 95 em 1880, e também em termos editoriais, com a diversificação dos assuntos abordados, uma conseqüência da ampliação dos interesses empresariais. A proliferação de jornais efetiva-se até 1908, com uma intensa movimentação jornalística, sobretudo no Rio de Janeiro, principal centro político do país.

\footnotetext{
${ }^{6}$ Embora a Gazeta do Rio de Janeiro tenha sido o primeiro jornal a ser publicado oficialmente em solo brasileiro, também no ano de 1808, alguns meses antes, havia sido lançado o jornal Correio Brasiliense, elaborado em Londres, mas distribuído no Brasil. Além da visão histórica sobre os acontecimentos, disponível em Bahia (1990), análises discursivas sobre os primeiros anos da imprensa no Brasil podem ser encontradas em Mariani (1993; 1999).
} 
Sob tais condições de produção, são publicadas as primeiras colunas sobre o saber lingüístico na imprensa brasileira. Tais colunas já se faziam presentes em jornais portugueses desde setembro de 1890, primeiro registro encontrado de publicações do filólogo Cândido de Figueiredo, com o pseudônimo João Caturra Júnior. As colunas veiculadas sob o pseudônimo são reunidas em livro no ano seguinte, em 1891, reeditado no mesmo ano ${ }^{7}$.

No Brasil, as primeiras colunas de Cândido de Figueiredo datam de abril de 1900, publicadas no Jornal do Comércio. Mais antigo jornal diário em circulação ininterrupta em toda a América Latina ${ }^{8}$, o Jornal do Comércio é fundado em 31 de agosto de 1827, por Pierre Plancher-Seignot, tipógrafo francês. Segundo Sodré (1977), Plancher-Seignot é um dos "numerosos franceses" que vieram para o Brasil após a fase da Independência e contribuíram para a expansão da imprensa no país. Inicialmente dedicado com exclusividade à divulgação de preços, notícias marítimas e relacionadas à importação e exportação, o Jornal do Comércio torna-se, a partir de 1828, um periódico de interesse geral e, poucos anos depois, segundo os registros de Bahia (1990), o jornal de maior expressão do país.

Com o objetivo de "explorar e ampliar o filão que vinha sendo praticamente monopolizado pelo Diário do Rio de Janeiro, e que lhe permitira superar o caráter efêmero dos jornais da época", segundo Sodré (1977, p. 126-127), a folha não se destinava apenas a dar melhor e maior divulgação às notícias comerciais (...) como a fornecer os elementos mais importantes do quadro político, assim, dos episódios principais daquela fase. ${ }^{9}$

É nesta tentativa de ampliar o campo de atuação dos periódicos de então que o Jornal do Comércio inicia a publicação das colunas de Cândido de Figueiredo, como as analisadas na seção seguinte deste trabalho, reservando o espaço denominado "O que se não deve dizer" ao debate de questões lingüísticas. Em dezembro do mesmo ano, Figueiredo também passa a assinar uma coluna no Diário de Notícias, em Portugal, embora, segundo o autor, o periódico português se caracterizasse por ser

\footnotetext{
${ }^{7}$ As colunas publicadas por Cândido de Figueiredo, com o uso do pesudônimo João Caturra Júnior, encontram-se reunidas no livro Lições Práticas da Língua Portuguesa, Volume I (FIGUEREIDO, 1891).

${ }^{8}$ De acordo com informação encontrada no site da empresa jornalística e em bibliografias sobre comunicação (JORNAL..., 2006; SODRÉ, 1977).

9 Atualmente de propriedade dos Diários Associados, o Jornal do Comércio mantém sua circulação em São Paulo, Rio de Janeiro, Brasília e Belo Horizonte. (JORNAL..., 2006).
} 
uma "folha essencialmente popular", o que exigia um texto diferenciado do publicado no Jornal do Comércio.

A repercussão das colunas de Figueiredo faz com que outros jornais adotem a mesma prática. É o caso do jornal Correio da Manhã, que em 26 de fevereiro de 1903 inicia a publicação da coluna intitulada "Notações Filológicas", de autoria do filólogo brasileiro Heráclito Graça. O jornal Correio da Manhã havia sido fundado em 1901, como uma forma de reação ao monopólio europeu nos periódicos e ao governo brasileiro da época. De propriedade do jornalista Edmundo Bittencourt, o periódico aceitava colaboradores das mais diversas tendências, e até a sua extinção, em 1974, caracterizou-se por ser um jornal de opinião ${ }^{10}$.

As colunas redigidas por Heráclito Graça encontram também lugar privilegiado no periódico Correio da Manhã e estabelecem um diálogo com os artigos que compõem a coluna "O que se não deve dizer", de Cândido de Figueiredo. Um diálogo que se constitui ao mesmo tempo em que confere à imprensa da época uma certa autoridade de dizer sobre a língua nacional, ainda que se servindo de especialistas em filologia para tal, e de fazer circular sentidos sobre a mesma.

Como afirma Pêcheux (1997), o lugar do dizer, ao possibilitar a formulação e a circulação dos discursos, é parte dos processos de constituição de sentido. A circulação que, segundo Orlandi (2001, p. 9), "se dá em certa conjuntura e segundo certas condições”, é o terceiro momento dos processos de produção do discurso, tão relevante quanto os momentos de sua constituição e formulação. Ao constituir-se enquanto um lugar de dizer sobre a língua portuguesa no Brasil, a imprensa coloca em circulação para um público específico questões antes restritas aos estudos filológicos e, neste movimento, participa da produção de novos sentidos sobre a língua e os seus usos.

Com a publicação das colunas sobre língua portuguesa redigida por filólogos, a imprensa, enquanto instituição, produz, formula e coloca em circulação um dizer sobre a língua portuguesa, participando assim de uma etapa de consolidação do idioma nacional. Ao analisar cronologicamente os estudos sobre o português enquanto língua nacional, Guimarães (2004) identifica quatro momentos distintos que, entretanto, podem ser descritos

\footnotetext{
${ }^{10}$ Segundo relatos do Dicionário Histórico-Biográfico Brasileiro (DICIONÁRIO..., 2006).
} 
em duas relações distintas entre Brasil e Europa. Nas palavras de Guimarães $(2004$, p. 44):

... podemos dizer que no primeiro (do século XVI a meados do XIX) temos todo um movimento caracterizado pela presença de Portugal no Brasil. Do segundo período em diante vê-se uma importante inversão. Trata-se de uma relação do Brasil relativamente à Europa e ao mundo ('ocidental').

Esta relação de proximidade e distanciamento entre o Brasil e a Europa, de forma mais evidente, Portugal, manifesta-se na definição da língua nacional e nos conflitos entre uma visão de incentivo ao purismo da língua portuguesa, pela aproximação com os clássicos, e de valorização às particularidades do falar brasileiro, marcadas enquanto brasileirismos na língua. A oposição entre a escrita dos clássicos e o falar do dia-a-dia é abordado nas colunas analisadas na próxima seção deste trabalho como o conflito entre o bem e o mal falar, entre o uso consagrado e as "invenções da imprensa". Produzidas em uma fase intermediária, entre os períodos marcados por relações distintas entre Brasil e Portugal, as colunas, produzidas por um português e por um brasileiro, materializam esta relação de, ao mesmo tempo, buscar as particularidades do português falado no Brasil, e não se distanciar dos clássicos da língua, de origem portuguesa.

\section{As primeiras colunas: o lugar do dizer sobre a língua na imprensa}

Com o objetivo de compreender o processo de constituição do espaço de dizer sobre a língua portuguesa na imprensa brasileira, a partir de 1900, bem como o funcionamento deste dizer, foram selecionadas como material de análise a primeira série de escritos dos filólogos Cândido de Figueiredo e a de Heráclito Graça, publicadas em periódicos brasileiros. As colunas assinadas por Figueiredo encontram-se reunidas na obra "O que se não deve dizer: bosquejos e notas de filologia portuguesa” (1903); os escritos de autoria de Heráclito Graça, por sua vez, compõem a obra "Factos da linguagem: esboço crítico de alguns assertos do Snr. Candido de Figueiredo" (1904). Segundo relatam os autores no prefácio das obras, as colunas foram reunidas em livro da forma como foram publicadas originalmente nos periódicos Jornal do Comércio e Correio da Manhã, respectivamente.

A análise das colunas aponta para a presença de um processo discursivo cujo funcionamento é marcado por relações de aproximação e distanciamento 
entre as formações imaginárias que o compõem. Tais relações se estabelecem entre as imagens do autor e da imprensa, da imprensa e dos usos diários da língua, e destes usos do português e dos clássicos da literatura, que no corpus analisado representam a própria língua portuguesa em sua suposta homogeneidade.

As formações imaginárias, compreendidas conforme Pêcheux (1997), determinam o lugar que os sujeitos dos discursos atribuem a si mesmos e ao outro durante a enunciação. Nos termos de Orlandi (2001, p. 40), são essas imagens, que resultam de projeções, que "permitem passar das situações empíricas - os lugares dos sujeitos - para as posições dos sujeitos no discurso". Nas colunas que compõem o corpus deste trabalho, as imagens do leitor, do escritor autor das colunas, da língua portuguesa e da própria imprensa se relacionam, aproximando-se e distanciando-se, em um movimento significativo para a compreensão da imprensa enquanto lugar de dizer sobre a língua.

Embora apresentem peculiaridades, uma vez que os artigos de Heráclito Graça são produzidos quase que constantemente em resposta aos de Cândido de Figueiredo, as colunas mantêm estrutura semelhante e constroem igualmente as imagens para o leitor, o autor das colunas, a língua portuguesa e a imprensa.

As publicações de Cândido de Figueiredo, em sua maioria, têm início com a apresentação do assunto a ser tratado, proveniente de "erros" cometidos no emprego da língua portuguesa. Segundo o autor, o seu objeto de interesse consiste na língua portuguesa, falada ou escrita, com as "incorreções e os delitos de linguagem" gerados pelo "hábito" e pela "rotina mais ou menos inconscientes". Em sua argumentação, associa tais "erros" e "incorreções” à imprensa e aos escritores contemporâneos, servindo-se, para tanto, de estudos etimológicos e de exemplos extraídos de obras consideradas clássicas da língua portuguesa.

Percurso semelhante é adotado por Heráclito Graça em suas colunas, já apresentadas ao leitor do jornal Correio da Manhã com o propósito de fornecer "reparos a alguns pontos filológicos e vernáculos do Sr. Cândido de Figueiredo". Desta forma, suas publicações têm início com a apresentação da questão gramatical presente em algum dos escritos do filólogo português, ou da imprensa da época, que, segundo o autor, estaria em contrariedade com os clássicos do idioma. Para iniciar a sua argumentação, descreve as afirmações feitas acerca da questão exposta por Cândido de Figueiredo, 
apontando o equívoco, e reforça o seu posicionamento com a citação de exemplos extraídos dos clássicos da língua portuguesa.

Em ambas as publicações, são projetadas a imagem de um leitor não especializado, o leitor comum, no intuito de, nas palavras de Cândido de Figueiredo, "servindo as letras, ser útil a quem menos saiba, pela forma que melhor se atenda e menos enfade, forma comezinha, simples, chã..." (1903, p. 13). Essa imagem do leitor é reforçada por Cândido de Figueiredo em outras de suas publicações que reúnem escritos divulgados inicialmente nas imprensas brasileira e portuguesa. Em "Falar e escrever - novos estudos práticos da língua portuguesa ou consultório popular de enfermidades da linguagem", obra publicada dois anos mais tarde, em 1905, o autor ressalta: "não escrevo para gente letrada: escrevo para quem sabe menos do que eu" (FIGUEIREDO, 1905, p. 7). Mais adiante, acrescenta que os seus escritos são "destinados ao vulgo anónimo, que não deseja saber muito, mas que deseja saber alguma coisa. Por isso lhe chamo consultório popular...”.

A mesma imagem para o leitor é projetada pelos escritos de Heráclito Graça, uma vez que as suas colunas destinam-se aos também leitores de Cândido de Figueiredo, àqueles a quem o filólogo português teria como objetivo "esclarecer e instruir" (GRAÇA, 1904, p. 8), mas que possam ter sido "induzidos ao erro" pelas falhas existentes nas colunas publicadas no Jornal do Comércio. Trata-se de um leitor que se confunde com o leitor diário dos periódicos não especializados, de interesse geral, e que se interessa pela língua portuguesa presente em seu dia-a-dia, da mesma forma que acompanha os noticiários e as colunas que abordam temas diversos, como política e economia.

Para esse leitor, entretanto, em vez da imagem do jornalista ou escritor de jornais, é apresentada a do filólogo, a de um estudioso da língua, com autoridade para dizer o que pode e o que não pode ser dito em língua portuguesa. A este lugar de dizer do especialista, entretanto, confronta-se a posição de escritor das colunas projetada no discurso sobre a língua nos jornais. Uma posição que não corresponde à do especialista capaz de dizer por si só, mas à daquele que conhece os clássicos da língua portuguesa e, com base na leitura prévia dos mesmos, está apto a dizer o que é permitido nos usos do idioma.

Para si, Figueiredo atribui, aparentemente, uma posição diferenciada da de gramático ou de filólogo. Em suas palavras: "Como não escrevo gramáticas, nem tratados filológicos, não costumo dar às minhas notas método 
ou ordem preestabelecida: registro factos ocorrentes, muitas vezes ao acaso, ressaltando amiúde de uma leitura de ocasião, da audição de um discurso, de tudo e de nada" (1905, p. 13). Apesar disso, o filólogo reserva a si mesmo a imagem de "estudioso", "publicista", "transmissor do que os sábios e a experiência ensinam sobre a língua”, noções que se confundem com a imagem que ele próprio atribui aos filólogos, a daqueles que "orientam para o bom uso da língua”. Vale ressaltar que o autor também produziria futuramente gramáticas e, anteriormente, elaborara dicionários, ainda que negue a si mesmo essa qualificação em suas publicações no jornal ${ }^{11}$.

A imagem de especialista em língua portuguesa atribuída ao autor das colunas na imprensa é projetada também nas publicações de Heráclito Graça que, apesar de destinar o espaço de suas colunas no jornal para apontar falhas cometidas por Cândido de Figueiredo, ressalta a erudição do filólogo português e o seu conhecimento sobre a língua. Tal imagem começa a ser projetada desde a primeira publicação de Heráclito Graça no jornal Correio da Manhã, uma carta destinada ao então redator do periódico, Leão Velloso Filho (Gil Vidal), publicada em 26 de fevereiro de 1903, em que o filólogo expõe os motivos de ter aceitado o convite para colaborar com o jornal. Em um dos trechos, afirma: "muito me edifica dizendo e suppondo V. que da publicação de meus pobres reparos a alguns pontos filologicos e vernaculos do Sr. Candido de Figueiredo virá proveito a quem em muitas aperturas procura o fio do labirinto da sciencia da linguagem portugueza..." (1904, p. 8).

Heráclito Graça assume, assim, a posição de leitor de Cândido de Figueiredo, mas a de um leitor especializado, pronto para intervir nas discussões propostas pelo filólogo português e apto a corrigi-lo em suas colocações sobre a língua portuguesa e os seus usos. Língua esta apresentada paradoxalmente como um produto dos clássicos, mas também dos usos diários, apontados como capazes de influenciá-la negativamente.

O diálogo estabelecido entre as colunas de Cândido de Figueiredo e Heráclito Graça, e mesmo as discordâncias quanto às questões lingüísticas entre os autores podem ser compreendidos se consideradas as condições históricas em que produzem, momento que antecede a definição de um

\footnotetext{
${ }^{11}$ Cândido de Figueiredo (1846-1925) é autor de dicionários, como o "Novo diccionario da lingua portuguesa”, publicado no final do século XIX (1899), e de gramáticas, como "Gramática das crianças" e "Gramática sintética da língua portuguesa”, entre outras publicações.
} 
conjunto de normas aplicáveis à língua portuguesa, conforme falada e escrita no Brasil, de forma a manter uma suposta homogeneidade da mesma. Historicamente, o final do século XIX e o começo do século XX constituem um momento de organização da sociedade brasileira e de proliferação de discussões acerca da organização do conhecimento sobre a língua. Conforme aponta Orlandi (2002, p. 192), é uma característica desta época a produção constante de gramáticas, que guardam entre si, além da diversidade de autoria e abordagem, "diferenças descritivas e analíticas; diferenças de análise de frases e de seus complementos, distinções que incidem sobre adjuntos e sua descrição etc".

Naquele momento, não havia um consenso quanto às características e nomeações de categorias da língua portuguesa trazida para o Brasil, submetida ao contato permanente com línguas indígenas e africanas, razão por que os filólogos serviam-se exclusivamente do recurso à citação dos considerados clássicos. Estes, por sua vez, não mostravam os mesmos usos para uma dada forma da língua, pois, como afirma Heráclito Graça, “... é tão vasto e basto o material dos nossos classicos”. A posição de autor da coluna confere, assim, a autoridade de comentador de língua na imprensa, um intermediário entre os clássicos e os usuários da língua no dia-a-dia.

A regulamentação de normas para língua, de forma a assegurar a sua suposta homogeneidade, ocorreria cerca de mais de 50 anos depois, em 1957/1958, com a publicação da NGB - Nomenclatura Gramatical Brasileira. Tal publicação exerce notada influência sobre a produção gramatical, uma vez que as gramáticas elaboradas anteriormente à sua publicação tiveram de ser reformuladas e adequadas às normas para manter-se em circulação, e também provoca efeitos na escrita sobre a língua portuguesa na imprensa. Com o estabelecimento de normas, descritas pela NGB, há uma mudança no processo de autoria dessas colunas, pois as regras ditam o que pode ou não pode ser dito, anulando a possibilidade de discordância entre os autores e reduzindo a autoridade de comentador de língua e conhecedor dos clássicos à de conhecedor da norma.

Quanto à imagem da língua, esta é construída de forma a apresentar a língua portuguesa como homogênea, em um dizer que a toma como um referente, materializado nos clássicos. Deste modo, a tudo o que é tema dos escritos de Cândido de Figueiredo e Heráclito Graça nas colunas sobre o saber lingüístico atribui-se a condição de não-língua portuguesa, uma vez que estaria em desacordo com o referencial apontado pelos clássicos (ainda 
que mesmo os filólogos apresentem discordâncias entre si, ao se apoiarem nos clássicos).

A materialização nos clássicos aciona uma visão normativa sobre a língua, enquanto representada primordialmente em determinadas obras da língua portuguesa. Tal visão é sustentada pelos autores não apenas nas colunas publicadas em periódicos, mas em seus percursos enquanto filólogos. Cândido de Figueiredo é responsável, entre outros, pela elaboração do "Novo diccionario da língua portuguesa", publicado no final do século XIX em Portugal e que, segundo Verdelho (2002), "completa o ciclo dos dicionários de acumulação". Estes dicionários têm como característica a valorização à quantidade da nomenclatura, recolhida por seus autores preferencialmente em clássicos da língua portuguesa. No caso de Cândido de Figueiredo, são pesquisados autores que tradicionalmente não haviam sido consultados para a elaboração dos dicionários, como os autores de teatro António Prestes, Jorge Ferreira de Vasconcelos e Simão Machado, e autores modernos, como José Agostinho, Castilho, Herculano e Camilo, conforme afirma Verdelho (2002) ao apresentar um breve histórico dos dicionários portugueses.

A atenção dada por Figueiredo à normatividade da língua também se faz presente em seu processo de elaboração do "Novo diccionario". Segundo Verdelho (2002, p. 44), as entradas do dicionário, que chegam a 110 mil, são acompanhadas "pela ausência quase geral de citações e por uma grande simplificação dos artigos", mas com a manutenção da "informação gramatical e filológica".

A predileção pelo que considera clássico da língua portuguesa também é marcada na biografia de Heráclito Graça. Advogado, magistrado, jurista, político, jornalista e filólogo, Graça viria a ocupar, a partir de 1906, a cadeira 30 da Academia Brasileira de Letras. Em sua biografia, apresentada na página da Academia na internet (ACADEMIA..., 2006), além das atividades ligadas à magistratura e à política, são destacados os estudos de língua portuguesa, como no excerto abaixo:

Além de tantas atividades, era no estudo da língua que ele encontrava maior satisfação, anotando pacientemente os clássicos e mais sistematicamente o Elucidário de Viterbo, ao fim do qual escreveu: "O Elucidário contém 6.143 vocábulos, foram acrescidos 7.457, perfazendo o total de 14.600 . 
Os filólogos Cândido de Figueiredo e Heráclito Graça observam, assim, a língua enquanto um produto acabado nos clássicos e mal utilizado no dia-a-dia pela população e pela imprensa. Nos termos de Cândido de Figueiredo (1903, p. 11), "quanto mais progressiva é a civilização de um povo, mais sujeita é a sua língua a deturpações e vícios, sob a variada influência das relações internacionais, dos novos inventos, das travancas da ignorância, e até dos caprichos da moda".

Aos filólogos seria atribuída a função de "zelar pela língua portuguesa" - por sua "saúde", como afirma Cândido de Figueiredo, com o emprego de metáforas, como ao nomear o seu espaço "consultório popular de enfermidades da língua" e ao afirmar que "também as letras padecem de micróbios, e nem sempre se perde o tempo em os observar pelo microscópio da sã doutrina e em lhes aplicar as drogas recomendadas pela farmacopéia dos mestres e pelas lições da experiência" (1903, p. 14).

Esta mesma formação imaginária, que toma a língua como passível de ser "depurada" no falar e o no escrever, sempre submetida "às regras", "à lógica" e "às tradições”, faz-se presente nos escritos de Heráclito Graça. Ao definir a sua posição de comentador sobre língua portuguesa, tomando como ponto de partida os escritos de Cândido de Figueiredo, Graça afirma que os seus trabalhos são “... inspirados pela mesma santa causa e ardente amor á pureza da língua materna...” (1904, p. 9) que os de Figueiredo.

Em suas colunas, entretanto, a noção de "erro" e "incorreção", empregada de forma intensa por Figueiredo, é deslocada das formas da língua para as "correções" apresentadas por Cândido de Figueiredo em suas colunas, sempre sustentada pela citação de clássicos. Ao tratar da forma "a par e passo", por exemplo, definida por Figueiredo como "tolice vulgarissima em gazetas", Graça afirma: "Nem a tradução é disparatada, nem tolice de escritores e noticiaristas de gazetas a locução a par e passo, que, entre outros escritores de nota, Garrett e Camillo Castello Branco perfilharam" (1904, p. 24). Ao apresentar posição oposta à de Figueiredo, discordando das considerações feitas pelo mesmo no tocante à expressão citada, Graça sustenta a imagem da língua como homogênea e atestada pelos clássicos da literatura, uma noção de língua que se mantém entre o certo e o errado, entre o que está nos clássicos e o que se faz presente no dia-a-dia.

Às imagens do leitor, do autor das colunas e da língua portuguesa somase à da imprensa, que ao assumir a condição de instituição social, passa, por intermédio dos filólogos, a "zelar" pela unidade da língua, ao mesmo 
tempo em que é responsabilizada pelas inovações e incorreções no uso da mesma. Esta imagem dupla da imprensa se faz presente em ambos os autores, desde a justificativa apresentada para a existência de seus comentários sobre a língua portuguesa nos periódicos. Cândido de Figueiredo atribui à imprensa a responsabilidade pelo que denomina "usos modernos" da língua portuguesa e "hábitos incorretos", ainda que tenha a mesma como intermediária entre os seus escritos e os leitores. É na imprensa e nos usos diários de linguagem que Figueiredo encontra o tema para as suas colunas e traz para as páginas do Jornal do Comércio a necessidade de normatizar a escrita das palavras.

Como afirma o autor em um de seus escritos: "Sábios e romancistas, poetas e prosadores, e nomeadamente a imprensa periódica, parece haverem conspirado para dar curso às mais extraordinárias invenções e enxertos de linguagem" (1903, p. 11). Mais adiante: "Alguns destes despautérios entraram de tal maneira nos hábitos da imprensa, que a correcção deles chega a produzir espanto nos escrevedores mais conscientes" (1903, p. 44). Ao discordar de Cândido de Figueiredo em muitas de suas colocações, Heráclito Graça "autoriza" alguns usos da imprensa condenados pelo filólogo português. Apesar disso, mantém-se na mesma posição de conhecedor da língua pelos clássicos, como se nota desde a carta de apresentação de seu trabalho no periódico, na qual apresenta a sua admiração ao trabalho desenvolvido por Figueiredo: “... procurei lêr e effectivamente li, admirando a profusão, brevidade e leveza dos capitulos, e perfilhando a doutrina delles em quasi tudo" (GRAÇA, 1904, p. 8).

A relação entre a imprensa e a questão lingüística evidencia-se já pela presença de filólogos entre os colaboradores dos principais periódicos da época, como uma forma de oposição à condição de responsável pelos "erros" no uso da língua, destacada nas colunas de Figueiredo e Graça, nas quais é dado destaque à abertura da imprensa aos usos de estrangeirismos e às formas populares do dizer. É nesse sentido que a imprensa enquanto instituição mantém-se em movimento, aproximando-se e distanciando-se do leitor e do filólogo, especialista em linguagem, ao constituir-se simultaneamente lugar do dizer do dia-a-dia e lugar de conhecimento lingüístico, ainda que em um espaço pré-determinado.

Ao dedicar espaço para o falar sobre a língua portuguesa, a imprensa insere-se em um círculo que serve à manutenção da idéia de homogeneidade da língua, ao mesmo tempo em que materializa a sua heterogeneidade. 
Dando voz ao filólogo, especialista em língua portuguesa e conhecedor dos clássicos, a imprensa traz para o cotidiano do leitor não especializado um certo conhecimento sobre a língua presente nos clássicos, ao mesmo tempo em que busca exemplos, motivação para o seu dizer na própria imprensa, que reflete os usos diários da língua. Desta forma, a prática da imprensa, enquanto instituição destinada ao controle da língua portuguesa, é de autosustentação.

\section{Considerações Finais}

A análise da trajetória da imprensa brasileira enquanto instituição, voltada à produção e circulação de sentidos sobre a língua portuguesa, aponta para a existência de duas fases em seu processo de constituição. A primeira tem início com o fim da censura prévia às publicações, em 1821, quando a questão da língua nacional começa a ser discutida nos periódicos em circulação nas principais cidades brasileiras, no contexto de debates sobre a unidade da nação e as decisões políticas. Já a segunda etapa se inicia com a dedicação de um espaço exclusivo às discussões sobre o saber lingüístico, o que se dá, segundo os registros encontrados, em 1900, com a publicação da primeira coluna sobre o saber lingüístico de autoria do filólogo Cândido de Figueiredo, no Jornal do Comércio.

A primeira fase identificada caracteriza-se pelo que pode ser considerada uma etapa de pré-institucionalização da imprensa, na qual a circulação de informações relativas ao saber lingüístico se dá de forma indireta, diluída em artigos que tratam de questões políticas pertinentes ao cenário nacional. Esta circulação se intensifica após 1870, quando as discussões sobre a educação brasileira colocam em pauta a língua nacional. A partir de 1900, com as publicações de Cândido de Figueiredo e, de 1903, com as respostas dadas ao filólogo português por Heráclito Graça, a imprensa constitui-se oficialmente como um lugar de dizer sobre a língua portuguesa, centrada na autoridade dos filólogos e no testemunho dos clássicos da literatura.

Neste momento, a imprensa, fazer tradicionalmente realizado por conhecedores das letras, aproxima-se da erudição ao abrir espaço para a discussão de questões de etimologia e tradições da língua portuguesa, por meio da colaboração dos filólogos. No movimento peculiar de sua constituição, entretanto, o faz por meio do tornar público um dizer antes restrito a especialistas em linguagem. Nesse sentido, afasta-se da linguagem própria a gramáticos e filólogos, embora projete a imagem do conhecedor da língua 
portuguesa em suas páginas para voltar-se ao leitor comum, conforme destacam Cândido de Figueiredo e Heráclito Graça em suas colunas.

As formações imaginárias que constituem as colunas analisadas neste trabalho apontam, desta forma, para uma proximidade entre as imagens projetadas para o leitor e os autores das colunas sobre o saber lingüístico, publicadas nos periódicos Jornal do Comércio e Correio da Manhã, no final do século XIX e começo do século XX. Ao compartilharem uma mesma imagem da língua portuguesa, marcada pela homogeneidade, leitor e autores das colunas aproximam-se pela imprensa, estabelecendo uma relação peculiar: o leitor encontra nas colunas produzidas pelos autores críticas ao falar do cotidiano, presente em suas atividades diárias e na própria imprensa; pela autoridade dos autores-filólogos, é remetido à imagem da língua contida nos clássicos e trazida também para a imprensa; uma imprensa que, assim, coloca-se a serviço de um saber especializado sobre a língua, ao mesmo tempo em que materializa os usos diários dessa língua que, conforme apontam os filólogos, aproxima-se da prática do leitor comum, mas distancia-se dos clássicos.

Nesse movimento constante de aproximação e distanciamento entre as formações imaginárias, a imprensa enquanto instituição dá início à formação de uma categoria de especialista em linguagem denominada por Orlandi (2002) "gramático de mídia". Segundo a autora, "em relação ao modo de existência da linguagem na sociedade e do conhecimento sobre ela, forma-se, de um lado, o profissional com a marca do especialista que tem como figura emblemática o gramático de mídia (de plantão) que faz sua função como informação do conteúdo da gramática de cunho normativo" (ORLANDI, 2002, p. 210). Estes especialistas aparecem com maior intensidade a partir de meados do século XX, com a prática do jornalismo de Divulgação Científica, em oposição ao "especialista acadêmico" que, segundo Orlandi, "se resguarda da mídia".

As colunas com publicação a partir do final do século XIX servem-se da imprensa enquanto instituição para aproximar o público leigo de questões lingüísticas, do conhecimento de língua proposto pelos filólogos, de uma visão sobre a língua portuguesa historicamente determinada no país à época. Com isso, antecipa-se à constituição de imagens que serão projetadas a partir do desenvolvimento de uma mídia especializada, voltada à divulgação do fazer científico.

Ao apoiar-se em um discurso que se apresenta como um dizer que se auto-sustenta, criando a ilusão da objetividade ao dar voz ao especialista 
(filólogo), que, por sua vez, dá voz aos clássicos, promove-se, na imprensa, um dizer sobre a língua que funciona por si mesmo, que apaga a sua constituição na/pela imprensa. Neste processo, promove-se o apagamento do fazer circular como produção de sentidos, como o silenciamento de sentidos possíveis e a formulação de outros.

A imprensa, enquanto instituição, participa da produção e da circulação de um discurso sobre a língua portuguesa que não mais se identifica ao dizer do filólogo enquanto produtor de instrumentos lingüísticos como gramáticas e dicionários. Trata-se do dizer do especialista na imprensa - o dizer da imprensa - paradoxalmente responsabilizada pelas mudanças que afastariam a língua portuguesa de suas origens. Um dizer que, ao produzir sentidos, também evita sentidos possíveis, como o da língua portuguesa na relação com os seus muitos sujeitos no Brasil.

\section{Referências Bibliográficas}

AUROUX, S. A revolução tecnológica da gramatização. Trad. Eni Puccinelli Orlandi. Campinas - SP: Editora da Unicamp, 1992.

BAHIA, J. Jornal. História e Técnica. História da imprensa brasileira. $5^{\mathrm{a}}$ ed. São Paulo: Ática, 1990.

FIGUEIREDO, C. Lições práticas da língua portuguesa. 10ª ed., v. 1, Lisboa: Livraria Clássica Editora, (1891).

. O que se não pode dizer. Bosquejos e notas de filologia portuguesa. $7^{\text {a }}$ ed., v. 1, Lisboa: Livraria Clássica Editora, (1903).

. Falar e escrever. Novos estudos práticos da língua portuguesa ou consultório popular de enfermidades da linguagem. $7^{\text {a }}$ ed., v. 1, Lisboa: Livraria Clássica Editora, (1905).

GRAÇA, H. Factos da linguagem: esboço crítico de alguns assertos do Snr. Candido de Figueiredo. Rio de Janeiro: Livraria de Viuva Azevedo \& C. Editores, (1904).

GUIMARÃES, E. Acontecimentos institucionais e estudos do português. In: História da Semântica: sujeito, sentido e gramática no Brasil. São Paulo: Pontes, 2004, p. 27-49.

JOANILHO, M.P.G. As metáforas da língua nacional. Tese de doutorado apresentada ao Instituto de Estudos da Linguagem (IEL), Unicamp. Campinas, 2005. 
MARIANI, B. Discurso e instituição: a imprensa. RUA, n. 5, Campinas - SP, 1999, p. 47-61.

. Os primórdios da imprensa no Brasil. In: ORLANDI, E.P. Discurso fundador: a formação do país e a construção da identidade nacional. Campinas: Pontes, 1993, p. 31-42.

ORLANDI, E.P. Língua e conhecimento lingüístico. Para uma história das idéias no Brasil. São Paulo: Cortez, 2002.

. Análise de discurso. Princípios e procedimentos. $3^{\text {a }}$ ed. Campinas: Pontes, 2001.

(Org.) História das idéias lingüísticas: construção do saber metalingüístico e constituição da língua nacional. São Paulo: Pontes; Unemat Editora, 2001a.

PÊCHEUX, M. Semântica e discurso: uma crítica à afirmação do óbvio. $3^{\text {a }}$ ed. Campinas: Editora da Unicamp, 1997.

SODRÉ, N.W. História da imprensa no Brasil. 2a ed. Rio de Janeiro: Edições do Graal, 1977.

VERDELHO, T. Dicionários portugueses, breve história. In: NUNES, J.H.; PETTER, M. História do saber lexical e constituição de um léxico brasileiro. São Paulo: Humanitas/FFLCH/USP; Pontes, 2002, p. 15-64.

Fontes Eletrônicas

ACADEMIA Brasileira de Letras - Heráclito Graça - Biografia. Disponível em <www.academia.org.br/abl/cgi/cgilua.exe/sys/start.htm?infoid=625\&si d=287\&tpl=printerview $>$. Acesso em 21 set. 2006.

DICIONÁRIO histórico-biográfico brasileiro. Disponível em $<$ http://www. cpdoc.fgv.br/dhbb/ verbetes_htm/5814_1.asp>. Acesso em 5 mai. 2006.

JORNAL do Commercio. Disponível em <www.jornaldocommercio.com. br>. Acesso em 20 jan. 2006.

PROJETO Memória da Leitura. Disponível em <http://www.unicamp.br/iel/ memoria /base_temporal/Metaliterario/index.htm>. Acesso em $1^{\circ}$ jul. 2006. 